\title{
Nusselt number correlation for turbulent heat transfer of helium- xenon gas mixtures
}

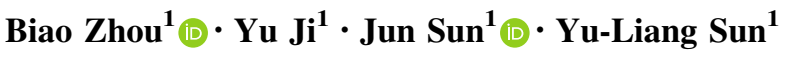

Received: 11 June 2021/Revised: 30 September 2021/Accepted: 11 October 2021/Published online: 20 November 2021

(C) The Author(s) 2021

\begin{abstract}
A gas-cooled nuclear reactor combined with a Brayton cycle shows promise as a technology for highpower space nuclear power systems. Generally, a heliumxenon gas mixture with a molecular weight of $14.5-40.0 \mathrm{~g} / \mathrm{mol}$ is adopted as the working fluid to reduce the mass and volume of the turbomachinery. The Prandtl number for helium-xenon mixtures with this recommended mixing ratio may be as low as 0.2 . As the convective heat transfer is closely related to the Prandtl number, different heat transfer correlations are often needed for fluids with various Prandtl numbers. Previous studies have established heat transfer correlations for fluids with medium-high Prandtl numbers (such as air and water) and extremely lowPrandtl fluids (such as liquid metals); however, these correlations cannot be directly recommended for such heliumxenon mixtures without verification. This study initially assessed the applicability of existing Nusselt number correlations, finding that the selected correlations are unsuitable for helium-xenon mixtures. To establish a more general heat transfer correlation, a theoretical derivation was conducted using the turbulent boundary layer theory. Numerical simulations of turbulent heat transfer for helium-xenon mixtures were carried out using Ansys Fluent. Based on simulated results, the parameters in the
\end{abstract}

This work was supported by the National Key Research and Development Program of China (No. 2018YFB1900501) and the CNSA program (No. D010501).

Jun Sun

sunjun@tsinghua.edu.cn

1 Institute of Nuclear and New Energy Technology, Key Laboratory of Advanced Reactor Engineering and Safety of Ministry of Education, Tsinghua University, Beijing 100084, China derived heat transfer correlation are determined. It is found that calculations using the new correlation were in good agreement with the experimental data, verifying its applicability to the turbulent heat transfer for helium-xenon mixtures. The effect of variable gas properties on turbulent heat transfer was also analyzed, and a modified heat transfer correlation with the temperature ratio was established. Based on the working conditions adopted in this study, the numerical error of the property-variable heat transfer correlation was almost within $10 \%$.

Keywords Gas-cooled nuclear reactor - Space nuclear power $\cdot$ Helium-xenon mixtures $\cdot$ Convective heat transfer $\cdot$ Nusselt number

$\begin{array}{ll}\text { Abbreviations } \\ x & \text { Axial distance from inlet } \\ i & \text { Inlet of tube } \\ y & \text { Radial distance from wall } \\ C & \text { Constant, } 0.3 \\ T & \text { Temperature } \\ u & \text { Axial velocity }(\mathrm{m} / \mathrm{s}) \\ v & \text { Radial velocity }(\mathrm{m} / \mathrm{s}) \\ q & \text { Heat flux }\left(\mathrm{W} / \mathrm{m}^{2}\right) \\ M & \text { Molar weight }(\mathrm{g} / \mathrm{mol}) \\ G & \text { Mass flux }\left(\mathrm{kg} / \mathrm{m}^{2} \mathrm{~s}\right) \\ f & \text { Darcy friction factor } \\ g_{\mathrm{c}} & \text { Conversion factor } \\ R_{\mathrm{g}} & \text { Gas constant for a gas } \\ u_{\tau} & \text { Friction velocity }(\mathrm{m} / \mathrm{s}) \\ r_{0} & \text { Radius of tube }(\mathrm{m}) \\ D & \text { Diameter of tube }(\mathrm{m}) \\ P e & \text { Peclet number, Pr } \cdot R e \\ P r_{\mathrm{t}} & \text { Turbulent Prandtl number, } \varepsilon_{\mathrm{m}} / \varepsilon_{\mathrm{h}} \\ y^{+} & \text {Non-dimensional wall distance }\end{array}$


$\mathrm{U}^{+} \quad$ Non-dimensional velocity, normalized by $u_{\tau}$

$P e_{\mathrm{t}} \quad$ Turbulent Peclet number, $\varepsilon_{\mathrm{m}} / v \cdot \mathrm{Pr}$

$\begin{array}{ll}\text { Subscript } \\ \mathrm{b} & \text { Bulk } \\ \mathrm{c} & \text { Center of tube } \\ \mathrm{w} & \text { Wall } \\ \mathrm{cp} & \text { Constant property } \\ \mathrm{vp} & \text { Variable property } \\ \infty & \text { Turbulent core region } \\ \mathrm{crit} & \text { Value of demarcation point } \\ \mathrm{T} & \text { Temperature } \\ \mathrm{Cal} & \text { Calculation } \\ \text { Exp } & \text { Experimental data } \\ \text { local } & \text { Local radial value }\end{array}$

\section{Introduction}

Deep-space exploration, a landing on Mars, and the construction of planetary bases will become established activities in the near future. The development of advanced and reliable space power will become hugely important in order to achieve these ambitious milestones. Compared to typical power sources used in space, such as chemical fuel cells or solar photovoltaic arrays, the space nuclear reactor power is characterized by wider power coverage and longer operating duration; as such, it is regarded as a promising technology for human space exploration [1-3]. Among existing technology roadmaps of space nuclear reactors, the gas-cooled nuclear reactor combined with a closed Brayton cycle is perceived as the most rational scheme for the system power exceeding $200 \mathrm{~kW}$ [4-6]; this is because it can achieve a higher energy conversion efficiency and a smaller specific mass. Typically, pure helium is adopted as the working fluid for the terrestrial Brayton cycle because of its excellent thermal and transport properties [7]. However, its small molecular weight inevitably results in a larger aerodynamic loading of the turbomachinery, which in turn increases the mass and volume of the system [8]. To reduce the aerodynamic loads and obtain an acceptable heat transfer capacity, a helium-xenon mixture with a molecular weight of $14.5-40.0 \mathrm{~g} / \mathrm{mol}$ is generally considered as the working fluid for Brayton cycles [9-13]. The Prandtl number $(\mathrm{Pr})$ of helium-xenon mixtures in this molecular weight range is approximately $0.21-0.30$, which is significantly lower than that of conventional air or water $(\operatorname{Pr}>0.70)$. For such low- $P r$ fluids, the thermal boundary layer is thicker, and the similarity of velocity and temperature will be disrupted. Hence, the convective heat transfer characteristics of low- $P r$ helium-xenon mixtures differ from those of fluids with medium-high Prandtl numbers. Previous studies have also shown that the Dittus-
Bolter (DB) [14] and Colburn equations [15] obtained from experimental data of those conventional fluids overpredicted the Nusselt number of low-Pr gas mixtures [16, 17]. Therefore, to better describe the convective heat transfer of helium-xenon mixtures, it is necessary to establish a suitable heat transfer correlation.

The particularity of flow and heat transfer for low- $\mathrm{Pr}$ fluids has been widely concerned [18-20]. However, most studies on this issue have mainly focused on liquid metals $(P r \cong 0.01)$, where many heat transfer correlations for liquid metals were proposed [21-23]. Lyon et al. [24] first derived a semi-empirical heat transfer correlation for a boundary condition with constant heat flux. Subsequently, Azer et al. [25] and Sleicher et al. [26] proposed their heat transfer correlations for liquid metals using theoretical hypotheses. Based on experimental data for liquid metals, Stomquist et al. [27], Skupinski et al. [28], and Churchill [29] presented their empirical heat transfer correlations. The $P r$ of liquid metals was found to be one or two orders of magnitude lower than that of the helium-xenon mixture; importantly, the flow and heat transfer characteristics of these two fluids significantly differed. To better illustrate the difference in convective heat transfer, Fig. 1 presents the temperature profiles of the air, helium-xenon mixture, and liquid mercury in a heated tube [30]. The temperature profile of the liquid metal was flat; however, the temperature distribution of the helium-xenon mixture was similar to that of air and relatively steep near the wall. These results show that the thermal resistance of liquid metal is evenly distributed on the radial section, indicating that heat transfer was dominated by molecular heat conduction. The thermal resistance of the helium-xenon mixture was concentrated in the limited near-wall region, and turbulent heat

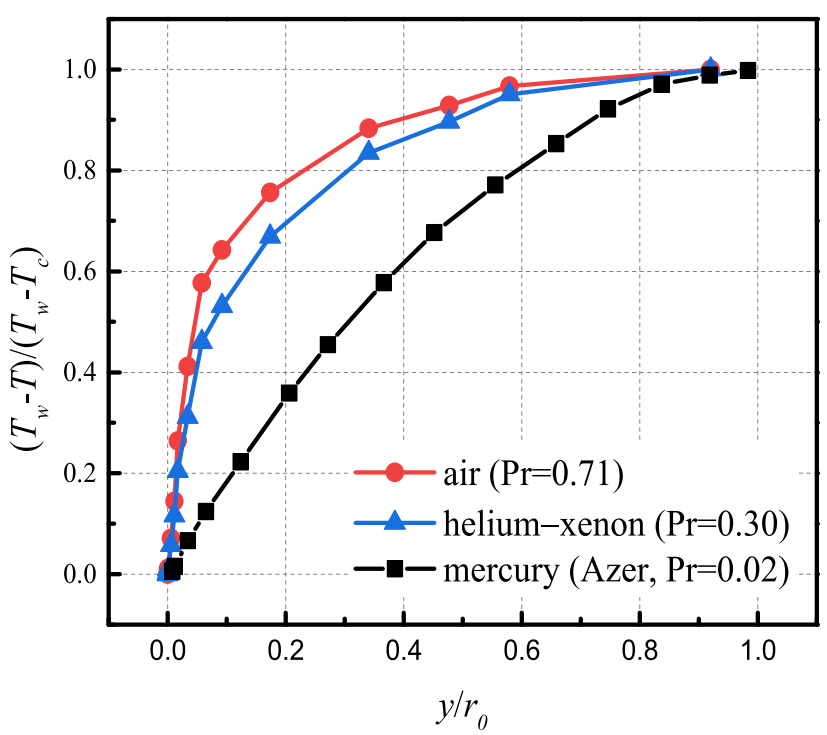

Fig. 1 (Color online) Temperature profiles of different fluids 
diffusion continued to be dominant. Due to the difference in flow and heat transfer, the heat transfer correlations from liquid metals could not directly be used to calculate flow and heat transfer for helium-xenon mixtures without verification. As such, there is a need to conduct in-depth research on the heat transfer correlation for helium-xenon mixtures within the $P r$ range.

This study evaluates the applicability of existing Nusselt number correlations to helium-xenon mixtures. Subsequently, a theoretical derivation of the Nusselt number correlation was conducted to establish a more general heat transfer correlation. Numerical simulations of the turbulent heat transfer for helium-xenon mixtures were also carried out; the simulated results were used to determine related parameters in the derived correlation. Finally, the effects of varying gas properties on turbulent heat transfer were considered, and a new property-variable heat transfer correlation was presented.

\section{Application of existing correlations}

Table 1 shows that this study selected common correlations and explored their applicability to helium-xenon mixtures. Among these correlations, DB and Colburn's correlations are empirical correlations obtained from experimental data relating to medium-high $\operatorname{Pr}$ fluids. Churchill's correlation was determined by numerically fitting experimental data for different fluids with a wide range of Prandtl numbers. The uncertainty associated with the above three correlations is provided in Table 1. The Lyon's and Stomquist's equations were frequently used for comparison in many studies on the convective heat transfer of liquid metals; however, clear uncertainties have rarely been provided for these equations in published literature. Additionally, it should be noted that the applicable range of most correlations in Table 1 was intentionally extrapolated to evaluate their suitability for helium-xenon mixtures.
Figure 2 shows that calculations were compared with experimental data [17]; the correlations from DB and Colburn had clearly overpredicted the Nusselt number of helium-xenon mixtures, while other calculations were underestimates compared with experimental data. Although predictions by Churchill's correlation were relatively closer to the experimental data when the Reynolds number $(R e)$ equaled 84000 , it still exceeded the error limit of $10 \%$ at $R e=34000$. This indicates that the selected correlations from liquid metals are unsuitable for helium-xenon mixtures.

\section{Theoretical derivation}

To propose a more universal Nusselt number correlation for helium-xenon mixtures, a theoretical derivation based on the turbulent boundary layer theory and eddy viscosity hypothesis was conducted. Obtaining the temperature profile was key to deriving the theoretical heat transfer correlation [31]. First, the derivation processes for the general logarithmic law of temperature was briefly reviewed. Ignoring the varying properties of gas mixtures, the wall shear stress and wall heat flux in the fully developed region may be expressed as follows [32]:

$\tau_{\mathrm{w}}=\rho\left(v+\varepsilon_{\mathrm{m}}\right) \frac{\partial \bar{u}}{\partial y}$,

$q_{\mathrm{w}}=\rho C_{\mathrm{p}}\left(\alpha+\varepsilon_{\mathrm{h}}\right) \frac{\mathrm{d}\left(T_{\mathrm{w}}-\bar{T}\right)}{\mathrm{d} y}$.

A two-layer model was used to simplify the boundary layer [33], in which the flow boundary layer was divided into linear and logarithmic regions. Similarly, the thermal boundary layer was divided into molecular conduction and turbulent conduction regions. The linear and molecular conduction regions were dominated by molecular viscosity (v) and molecular heat diffusivity $(\alpha)$, respectively, neglecting the effect of turbulent momentum diffusivity
Table 1 Existing correlations of Nusselt number

\begin{tabular}{llll}
\hline Name & Correlations & $\begin{array}{l}\text { Range of } \\
\text { application }\end{array}$ & $\begin{array}{l}\text { Max } \\
\text { deviation }\end{array}$ \\
\hline $\begin{array}{l}\text { Dittus-Bolter et al. } \\
\quad \text { 14] }\end{array}$ & $N u=0.023 \operatorname{Re}^{0.8} \operatorname{Pr}^{0.4}$ & $0.7 \leq \operatorname{Pr} \leq 120$ & $\pm 20 \%$ \\
$\begin{array}{l}\text { Colburn [15] } \\
\text { Churchill [29] }\end{array}$ & $N u=0.023 \operatorname{Re}^{0.8} \operatorname{Pr}^{1 / 3}$ & $0.5 \leq \operatorname{Pr} \leq 100$ & $\pm 25 \%$ \\
& $N u=6.3+\frac{0.079 \operatorname{Re} \sqrt{f} \operatorname{Pr}}{\left(1+\operatorname{Pr}^{0.8}\right)^{5 / 6}}$ & $0.001 \leq \operatorname{Pr} \leq 200$ & $\pm 30 \%$ \\
Stomquist et al. [27] & $N u=3.6+0.025(\operatorname{Pr} \operatorname{Re})^{0.8}$ & & \\
Lyon [24] & $N u=7.0+0.025(\operatorname{PrRe} / 2)^{0.8}$ & $\operatorname{Pr}<0.1$ & - \\
\hline
\end{tabular}




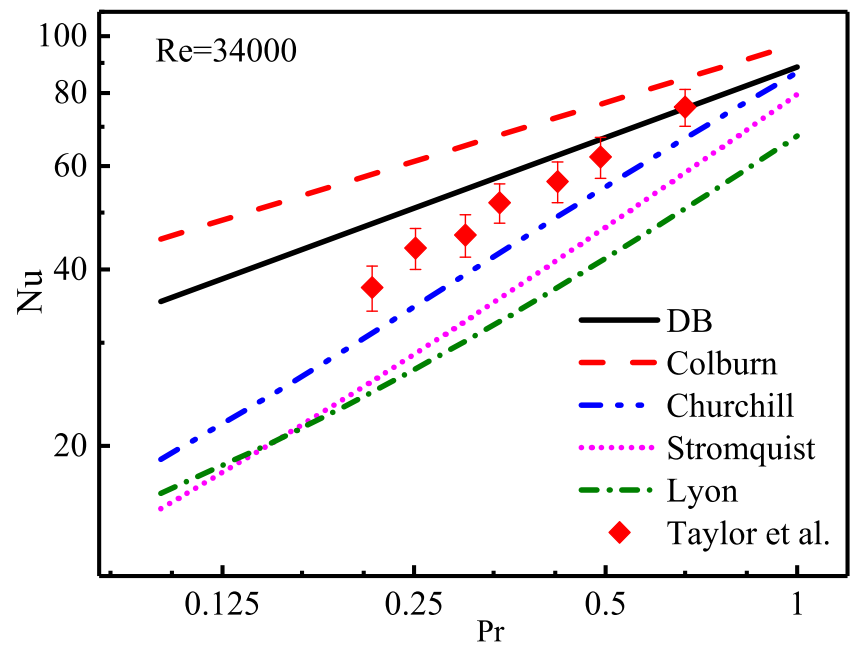

(a)

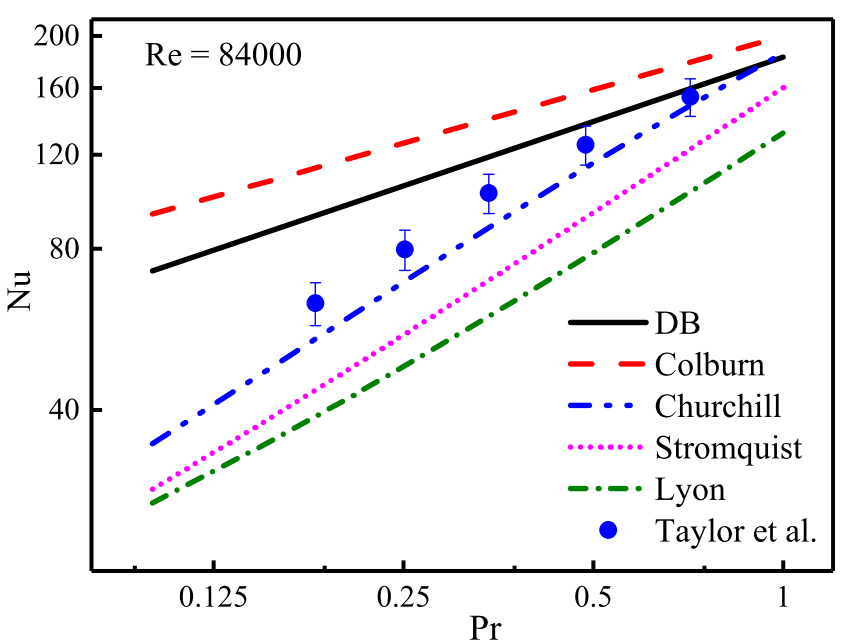

(b)

Fig. 2 (Color online) Predictions of Nusselt number by various correlations

$\left(\varepsilon_{\mathrm{m}}\right)$ and turbulent heat diffusivity $\left(\varepsilon_{\mathrm{h}}\right)$. Conversely, turbulent diffusion predominates in the logarithmic and turbulent conduction regions, thus ignoring molecular viscosity and molecular heat diffusivity, respectively. Using the mixing-length theory [34], the profile of dimensionless velocity may be derived by integration as follows:

$\begin{cases}U^{+}=y^{+}, & y^{+} \leq y_{\text {cirt }}^{+} \\ U^{+}=\frac{\ln \left(y^{+} / y_{\text {cirt }}^{+}\right)}{\kappa}+y_{\text {cirt }}^{+}, & y^{+}>y_{\text {cirt }}^{+}\end{cases}$

where $y_{\text {cirt }}^{+}$denotes the demarcation point between the linear and logarithmic regions, and $\kappa$ denotes the Karman constant. Based on the definition of turbulent Prandtl number $\left(P r_{\mathrm{t}}\right)$, Eq. (2) may be normalized, and the profile of dimensionless temperature can be acquired [35], as follows:

$\begin{cases}T^{+}=\operatorname{Pry}^{+}, & y^{+} \leq y_{\text {cirt }, \mathrm{T}}^{+} \\ T^{+}=\frac{\operatorname{Pr}_{\mathrm{t}} \ln \left(y^{+} / y_{\text {cirt }, \mathrm{T}}^{+}\right)}{\kappa}+\operatorname{Pry}_{\text {cirt }, \mathrm{T}}^{+}, & y^{+}>y_{\text {cirt }, \mathrm{T}}^{+}\end{cases}$

where $y_{\text {cirt. T }}^{+}$is the demarcation point between the molecular conduction and turbulent conduction regions, the above derivation is reported in several studies [36, 37]. Many empirical logarithmic laws of temperature have been proposed using regression analysis of experimental data. However, these empirical correlations lack a theoretical basis, and as such, their scope of application is limited. There is also an absence of relevant radial experimental data for helium-xenon gas mixtures in the current literature.

Therefore, in present investigation, the derivation of Eq. (4) was sequentially conducted to obtain the dimensionless mass-average temperature $\left(T_{\mathrm{b}}^{+}\right)$and the theoretical
Nusselt number correlation. To facilitate this derivation, it was assumed that the thickness of the linear and molecular conduction regions was small and therefore negligible. One study reported that the demarcation point of the flow boundary layer was almost fixed [32]; that is, $y_{\text {crit }}^{+}=11$, where $y^{+}$was defined as per Eq. (5):

$y^{+}=\frac{u_{\tau} y}{v}=\frac{\sqrt{\tau_{\mathrm{w}} / \rho}}{v} y$.

In which the wall shear $\left(\tau_{\mathrm{w}}\right)$ may be expressed as follows:

$\tau_{\mathrm{w}}=f \frac{\rho u_{\mathrm{b}}^{2}}{8}$.

By adopting the Blasius formula to calculate the friction factor $(f)$, the expression of $y^{+}$can be simplified to Eq. (7):

$y^{+}=\frac{u_{\mathrm{b}} \sqrt{f / 8}}{v} y=\frac{0.2 R e^{-0.125} u_{\mathrm{b}}}{v} y$.

In which $R e=\frac{u_{\mathrm{b}}}{v_{\mathrm{b}}} D$. The bulk viscosity $\left(v_{\mathrm{b}}\right)$ can be approximated to local viscosity $(v)$, and as there is no significant difference in magnitude, then:

$y^{+}=0.2 \operatorname{Re}^{0.875} \frac{y}{D}$.

Using this, the ratio of the height of the demarcation point ( $r$ ) from the wall to the diameter of the tube may be estimated. For $y_{\text {crit }}^{+}=11, r / D=0.035$ when $R e=10000$ and $r / D=0.0086$ when $R e=50000$; this indicates that the linear region in the tube is a very thin layer. As such, it is reasonable to dismiss the thickness of the linear region when carrying out integration derivation. Additionally, Zhao et al. [38] proposed a correlation to describe the relationship between $y_{\text {crit, } \mathrm{T}}^{+}$and $y_{\text {crit }}^{+}$as: 
$y_{\text {crit }, \mathrm{T}}^{+}=\frac{P r_{\mathrm{t}}}{P r} y_{\text {crit }}^{+}$.

Although this method may not be optimal for heliumxenon mixtures with $0.21 \leq P r \leq 0.30$ (as per this study), it may be used as a rough estimate. When $P r_{\mathrm{t}}=0.9$, then $y_{\text {crit, } \mathrm{T}}^{+}$is $33.0<y_{\text {crit, } \mathrm{T}}^{+}<47.1$; when combined with Eqs. (8) and (9), it is possible to calculate the ratio of the height of the demarcation point for the thermal boundary layer $\left(r_{\mathrm{t}}\right)$ from the wall to the diameter of the tube. Specifically, $r_{\mathrm{t}} / D=0.052 \sim 0.075$ when $R e=10000$, and $r_{\mathrm{t}} / D=0.013 \sim 0.018$ when $\operatorname{Re}=50000$, which indicates that the molecular heat conduction region takes up a small proportion of area in the tube; as such, it is reasonable to ignore the thickness of the molecular heat conduction region.

At the wall surface (i.e., $y=0$ ), the axial velocity is reduced to zero. At the center of tube (i.e., $y=r_{0}$ ), the axial velocity is the highest and can be described as follows:

$U_{\max }^{+}=\frac{1}{\kappa} \ln r_{0}^{+}+y_{\text {crit }}^{+}-\frac{1}{\kappa} \ln y_{\text {crit }}^{+}$.

By integrating the area under Eq. (3), the expression of dimensionless area-average velocity, $U_{\mathrm{a}}^{+}$, can be obtained:

$U_{\mathrm{a}}^{+}=\frac{\int_{0}^{r_{0}} U^{+} \cdot 2 \pi r \mathrm{~d} r}{\pi r_{0}^{2}}$.

By subtracting Eqs. (10) from (11), the following relationship can be obtained:

$U_{\mathrm{a}}^{+}-U_{\max }^{+}=\frac{2}{\kappa r_{0}^{2}} \int_{0}^{r_{0}}\left[r \ln \left(r_{0}-r\right)-r \ln r_{0}\right] \mathrm{d} r=\frac{-3}{2 \kappa}$.

Similarly, expressions for dimensionless temperature at the center $\left(T_{\max }^{+}\right)$can be derived as follows:

$T_{\max }^{+}=\frac{P r_{\mathrm{t}}}{\kappa} \ln \frac{r_{0}^{+}}{y_{\text {crit, } \mathrm{T}}^{+}}+\operatorname{Pr} y_{\text {crit, } \mathrm{T}}^{+}$.

Furthermore, the relationship between $T_{\max }^{+}$and the dimensionless area-average temperature, $T_{\mathrm{a}}^{+}$, can be obtained using Eq. (14):

$T_{\mathrm{a}}^{+}-T_{\max }^{+}=\frac{-3 P r_{\mathrm{t}}}{2 \kappa}$.

Combining Eqs. (12)-(14), the expression for $T_{\mathrm{a}}^{+}$can be derived using Eq. (15):

$T_{\mathrm{a}}^{+}=P r_{\mathrm{t}} U_{\mathrm{a}}^{+}-\frac{P r_{\mathrm{t}}}{\kappa} \ln y_{\text {crit, } \mathrm{T}}^{+}+P r y_{\text {crit }, \mathrm{T}}^{+}+\frac{P r_{\mathrm{t}}}{\kappa} \ln y_{\text {crit }}^{+}$

$$
-P r_{\mathrm{t}} \ln y_{\text {crit }}^{+} \text {. }
$$

However, to derive the theoretical correlation of the Nusselt number, the $T_{\mathrm{b}}^{+}$still needs to be determined. Several previous studies [39] have assumed that $T_{\max }^{+}$as
$T_{\mathrm{b}}^{+}$, because differences between the two parameters were $<10 \%$ for turbulent heat transfer as per Kays et al. [32]. In the present study, it was assumed that $T_{\mathrm{b}}^{+}=T_{\mathrm{a}}^{+}$to further reduce deviation. Specifically, a correlation to calculate $T_{\mathrm{b}}^{+}$was proposed based on theoretical derivation [39], as:

$T_{\mathrm{b}}^{+}-T_{\max }^{+}=\frac{3 P r_{\mathrm{t}}}{2 \kappa^{2}} \sqrt{\frac{f}{8}}-\frac{3 P r_{\mathrm{t}}}{2 \kappa}$.

Combine Eqs. (14) and (16), then,

$\frac{T_{\mathrm{a}}^{+}}{T_{\mathrm{b}}^{+}}=1-\frac{3 P r_{\mathrm{t}} N u}{2 \kappa^{2} \operatorname{RePr}}$.

Based on a working condition with $R e=30000$ and $\operatorname{Pr}=0.30$, where the Churchill correlation was used to calculate the Nusselt number, the second term on the right of Eq. (17) equals 0.030 and decreases with an increase in $R e$; as such, it was reasonable to assume $T_{\mathrm{b}}^{+}=T_{\mathrm{a}}^{+}$.

Using the definition of Nusselt number and $T^{+}$, the Nusselt number correlation may be transformed as follows:

$\left\{\begin{array}{l}N u=\frac{q_{\mathrm{w}}}{T_{\mathrm{w}}-T_{\mathrm{b}}} \frac{D}{\lambda} \\ T^{+}=\frac{\rho C_{\mathrm{p}} u_{\tau}\left(T_{\mathrm{w}}-T\right)}{q_{\mathrm{w}}} \Rightarrow N u=\frac{\operatorname{RePr} \sqrt{f / 8}}{T_{\mathrm{b}}^{+}}, \\ f=8 \tau_{\mathrm{w}} / \rho u_{\mathrm{b}}^{2}\end{array}\right.$

where $f$ is the friction factor. Combining Eqs. (15) and (18), the following theoretical expression for the Nusselt number was obtained:

$$
N u=\frac{\operatorname{RePr} \sqrt{f / 8}}{P r_{\mathrm{t}} \sqrt{8 / f}-\frac{P r_{\mathrm{t}}}{\kappa} \ln y_{\mathrm{crit}, \mathrm{T}}^{+}+P r y_{\text {crit }, \mathrm{T}}^{+}+\frac{P r_{\mathrm{r}}}{\kappa} \ln y_{\text {crit }}^{+}-P r_{\mathrm{t}} y_{\text {crit }}^{+}} .
$$

Equation (19) shows that the appropriate $f, y_{\text {crit }}^{+}, y_{\text {cirt T }}^{+}$, and average $P r_{\mathrm{t}}$ still need to be determined in order to obtain the new Nusselt number correlation. To do this, numerical simulations of turbulent heat transfer for helium-xenon mixtures were carried out, and these parameters were determined using the simulation results.

\section{Numerical simulations}

\subsection{Thermophysical and transport properties}

Accurate properties of helium-xenon mixtures are essential to numerical simulations. Typically, existing designs of space gas-cooled nuclear reactor systems have an operating pressure of $2 \mathrm{MPa}$ and a temperature range of approximately $400-1300 \mathrm{~K}$. Under these conditions, the theory of diluted gases based on the Chapman-Enskog approach was not found to be applicable. Tournier et al. 
[40] reviewed the experimental data for the properties of dense noble gas mixtures across a pressure range of 0.1-20 MPa and temperature up to $1400 \mathrm{~K}$, summarizing semi-empirical property correlations. Based on the study of Tournier et al. [40], a property-calculation code for helium-xenon mixtures was developed, and its accuracy was validated in a previous study [30]. Figure 3 presents the calculation of variations in gas mixture properties with temperature.

These results indicate that variations in thermal conductivity $(\lambda)$ and dynamic viscosity $(\mu)$ are proportional to temperature, while the specific heat capacity $\left(C_{\mathrm{p}}\right)$ and density $(\rho)$ decrease as temperature increases. As the value of the specific heat capacity varies very slightly with temperature, it can be set as a constant for a particular gas mixture in numerical simulations. Other property correlations were implemented in Ansys Fluent using user-defined functions.

\subsection{Numerical approach}

The turbulent heat transfer of the helium-xenon mixtures in a tube was simulated using Ansys Fluent. The calculation model refers to the test section of the experiment in Taylor et al. [17], as shown in Fig. 4.

The experimental loop was a closed circuit driven by a gas booster pump; the flow and heat transfer of the gas mixture was investigated in the test section. Figure $4 b$ shows the geometric parameters of the test section, which consisted of a straight tube with an inner diameter $(D)$ of $5.87 \mathrm{~mm}$. The total length $(L)$ was $680.92 \mathrm{~mm}$, of which the first part $\left(L_{1}\right)$ was adiabatic, while the remainder was heated by a resistance wire to obtain uniform heat flux. A two-dimensional calculation domain was adopted, as the gravitational effect was neglected.

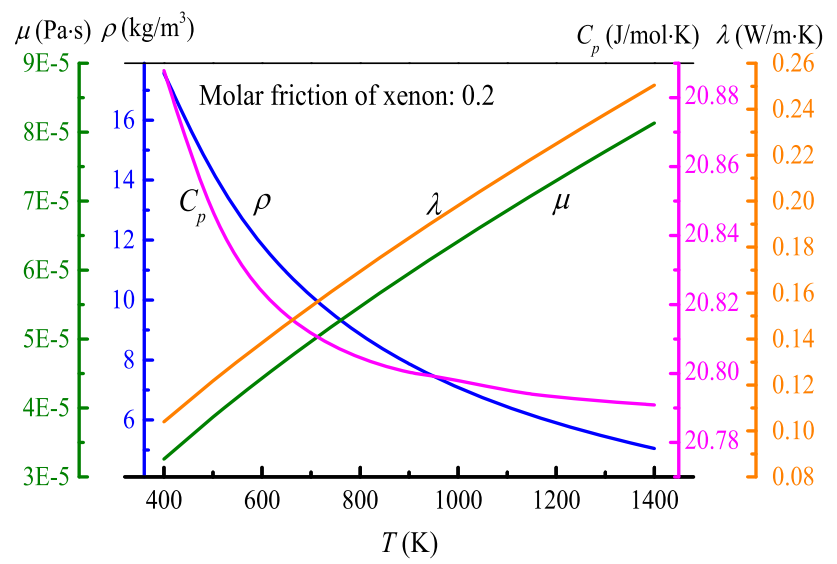

Fig. 3 (Color online) Variations in the properties of helium-xenon mixtures with temperature at $P=2 \mathrm{MPa}$
With respect to the simulated boundary conditions, the inlet was set to 'mass-flow-inlet', the outlet was set to 'pressure-out', and the wall surface adopted a non-slip boundary. The simulation parameters were set according to experimental conditions, listed in Table 2. A previous paper [41] evaluated the applicability of different turbulence models to helium-xenon mixtures; based on the findings from this paper, the $S S T \kappa-\omega$ turbulence model was selected for this study. To improve the accuracy of the numerical simulation for turbulent heat transfer of low- $\mathrm{Pr}$ helium-xenon mixtures, a local $\operatorname{Pr}_{\mathrm{t}}$ model (shown in Eqs. (20) and (21)), was proposed in Zhou et al. [30]. Based on comparison with more experimental data, in this study the first constant in the expression of $\operatorname{Pr}_{\mathrm{t}, \infty}$ was adjusted slightly from the original 0.80 to 0.86 .

$$
\begin{aligned}
P r_{\mathrm{t}} & =1 /\left\{\frac{1}{2 P r_{\mathrm{t}, \infty}}+C P e_{\mathrm{t}} \sqrt{\frac{1}{P r_{\mathrm{t}, \infty}}}-\left(C P e_{\mathrm{t}}\right)^{2}\right. \\
& \left.\times\left[1-\exp \left(\frac{-1}{C P e_{\mathrm{t}} \sqrt{P r_{\mathrm{t}, \infty}}}\right)\right]\right\} \\
P r_{\mathrm{t} \infty} & =0.86+\frac{30}{\operatorname{Re}_{\text {local }}^{0.888} \cdot P r}, \quad R e_{\text {local }}=\frac{u \cdot D}{v}
\end{aligned}
$$

Grid independence verification was investigated to ensure the validity of the numerical calculation. Four mesh files were tested: mesh1: $20 \times 3000$, mesh2: $30 \times 4000$, mesh3: $40 \times 6000$, and mesh4: $60 \times 8000$. The bulk temperature $\left(T_{\mathrm{b}}\right)$ of helium-xenon mixtures and the wall temperature $\left(T_{\mathrm{w}}\right)$ at $x=0.45,0.55,0.60$, and $0.65 \mathrm{~m}$ were calculated. Figure 5 shows that when the grid number exceeded 120 000, the difference in the bulk and wall temperatures as calculated by various meshes was negligible, and the maximum error was $<0.8 \%$. Based on the calculation accuracy and efficiency, mesh 3 was adopted in this study.

Figure 6 presents the grid of mesh 3 ; the grid refinement was applied in the near-wall region, where the spacing of the first grid was $0.004 \mathrm{~mm}$, spacing ratio was 1.08 , and maximal aspect ratio was 28.4. Using the Run696 as an example, the corresponding $y^{+}$of the first grid was $y^{+}$ $=0.22$. In fact, the wall-resolved method was enabled for the SST $\kappa-\omega$ model when the mesh in the near-wall region was sufficient. At that time, the $y^{+}$of the first grid was generally required to be $<1.0$; as such, mesh 3 was able to meet the calculation requirements. In order to further verify the simulation models adopted in the present study, additional experimental data on turbulent heat transfer for helium-xenon gas mixtures were introduced for comparison. Figure 7 shows that the calculated deviation of the wall temperature under various working conditions was essentially $5 \%$. Therefore, the modified turbulence model 
Fig. 4 (Color online) Test section of experiment for helium-xenon mixtures by Taylor et al. a Schematic diagram of experimental device; b Heated tube of test section

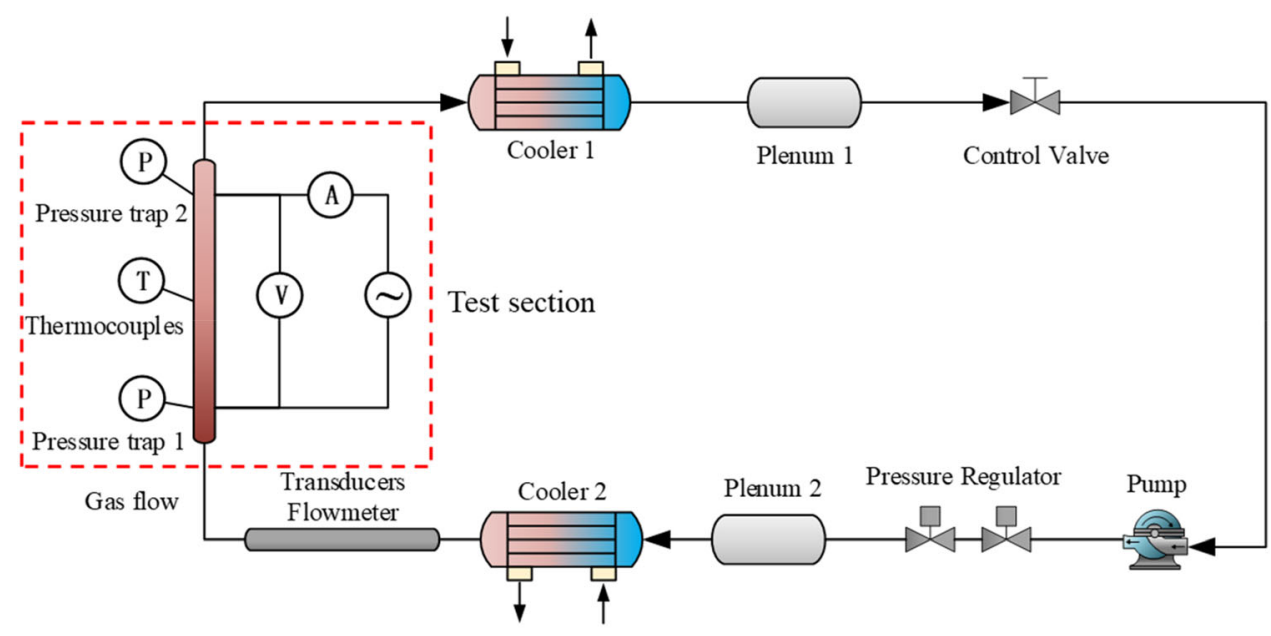

(a)

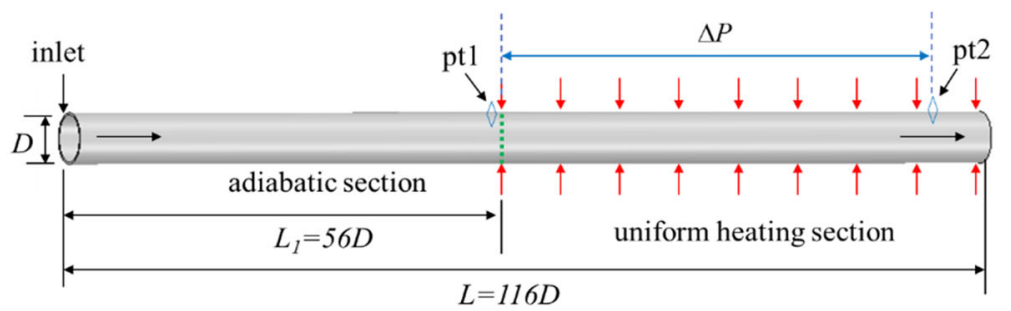

(b)

Table 2 Simulation parameters of helium-xenon mixtures

\begin{tabular}{llllcll}
\hline$M(\mathrm{~g} / \mathrm{mol})$ & No & $P r$ & $R e_{\mathrm{i}}$ & $q\left(\mathrm{~W} / \mathrm{m}^{2}\right)$ & $T_{\mathrm{w}} / T_{\mathrm{b}}(\mathrm{max})$ & $P_{\text {out }}(\mathrm{Pa})$ \\
\hline 14.5 & Run711 & 0.30 & 40,869 & 45,712 & 1.15 & 993,150 \\
& Run712 & 0.30 & 40,554 & 97,522 & 1.32 & 982,023 \\
& Run713 & 0.30 & 35,374 & 175,055 & 1.61 & 828,120 \\
& Run714 & 0.30 & 38,962 & 242,158 & 1.84 & 810,084 \\
& Run715 & 0.30 & 34,042 & 296,622 & 2.04 & 806,581 \\
& Run707 & 0.23 & 53,390 & 157,094 & 1.67 & 928,019 \\
& Run709 & 0.23 & 48,411 & 240,978 & 2.06 & 835,497 \\
& Run710 & 0.23 & 49,001 & 33,809 & 1.16 & 779,391 \\
& Run696 & 0.21 & 36,183 & 136,770 & 1.99 & 563,474 \\
& Run698 & 0.21 & 34,280 & 78,313 & 1.59 & 502,892 \\
& Run700 & 0.21 & 34,865 & 18,151 & 1.15 & 465,129 \\
& Run704 & 0.21 & 59,851 & 31,593 & 1.17 & 771,105 \\
& Run705 & 0.21 & 61,772 & 159,072 & 1.77 & 990,763 \\
& Run687 & 0.25 & 85,802 & 43,637 & 1.42 & 471,502 \\
& Run689 & 0.25 & 87,373 & 96,326 & 1.89 & 480,141 \\
& Run693 & 0.25 & 33,513 & 37,260 & 1.62 & 262,358 \\
\hline
\end{tabular}

may be used to study the turbulent heat transfer characteristics of helium-xenon mixtures.

\subsection{Determination of parameters}

There is a need to analyze the momentum diffusion characteristics of helium-xenon mixtures to determine the $y_{\text {crit }}^{+}$of the flow boundary layer. At the position of $y_{\text {crit }}^{+}$, the turbulent momentum diffusion should be equal to the molecular momentum diffusion. Figure 8 shows that the molecular viscosity $(v)$ and turbulent momentum diffusivity $\left(\varepsilon_{\mathrm{m}}\right)$ of helium-xenon mixtures with two different mixing ratios in the fully developed region $(x=600 \mathrm{~mm})$ 


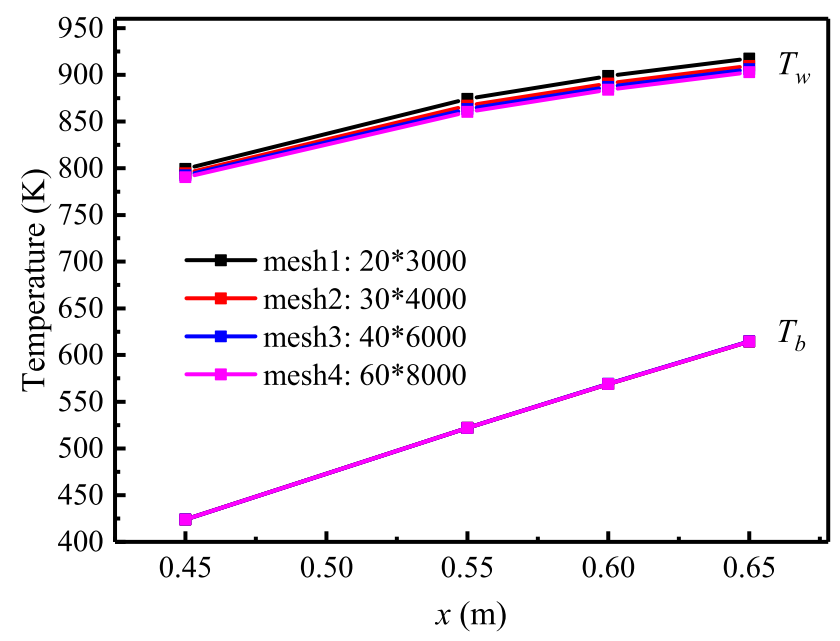

Fig. 5 (Color online) Simulated bulk temperature $\left(T_{\mathrm{b}}\right)$ and wall temperature $\left(T_{\mathrm{w}}\right)$ with various meshes

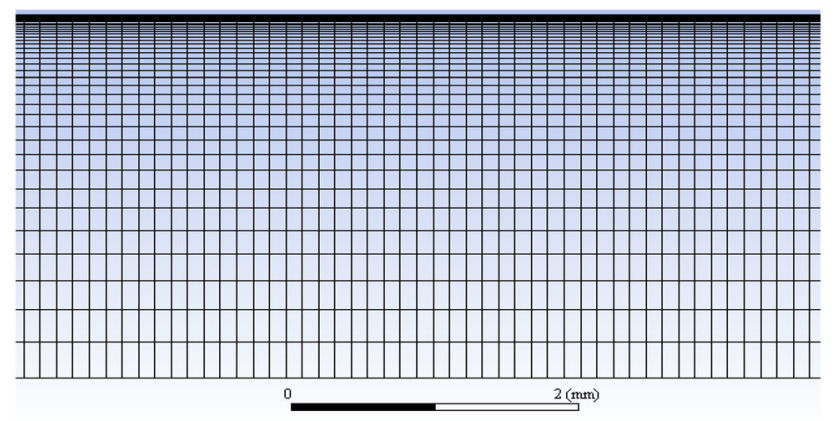

Fig. 6 (Color online) Grid of mesh3

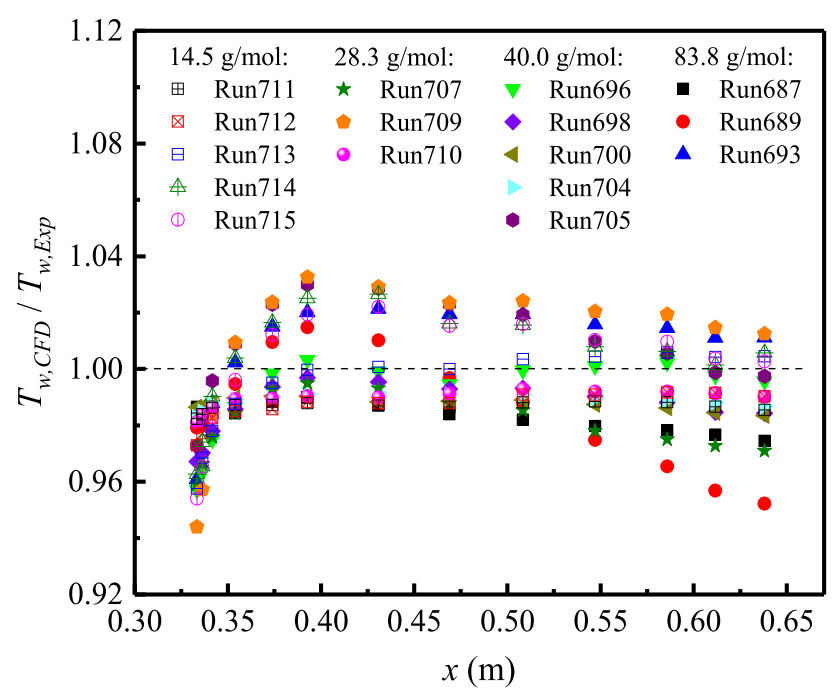

Fig. 7 (Color online) Comparison of simulated wall temperature $\left(T_{\mathrm{w}}\right)$ by the modified turbulent model and experimental data

were calculated. The results show that the intersections of the curves $\left(v=\varepsilon_{\mathrm{m}}\right)$ were always close to $y^{+}=11$; as such, the demarcation points of the flow boundary layer for the helium-xenon mixtures were determined to be $y_{\text {crit }}^{+}=11$.
Notably, the demarcation points of the flow boundary layer for water and air were also at approximately $y^{+}=11$ in Schlichting et al. [33]. These results indicate that Pr has little effect on the turbulent momentum diffusion of fluids.

To investigate the appropriate equation for the friction factor $(f)$, four typical equations from conventional fluids [42-44] (see Table 3), were selected for testing. One study [16] suggested that the experimental friction factor of noble binary gases may be calculated using Eqs. (22)-(24). The term $f$ is the overall average friction factor, calculated using the distance from the start of the heated section to the second pressure tap ('pt2' in Fig. 4):

$\Delta P_{\mathrm{f}}=\Delta P-\Delta P_{\mathrm{m}}$,

$\Delta P_{\mathrm{m}}=\frac{G^{2} R_{\mathrm{g}}}{g_{\mathrm{c}}}\left(\frac{T_{\mathrm{b} 2}}{P_{2}}-\frac{T_{\mathrm{b} 1}}{P_{1}}\right)$,

$f=\frac{2 \Delta P_{\mathrm{f}} \bar{\rho} D}{l G^{2}}$,

where $\Delta P$ denotes the total pressure drop; $\Delta P_{\mathrm{m}}$ denotes the acceleration pressure drop; and $\Delta P_{\mathrm{f}}$ denotes the friction pressure drop. Figure 9 shows that the calculated values were relatively close to each other and calculation errors were generally within $5 \%$. Based on the good agreement between the experimental data and the concise expression, the Blasius equation was used to calculate the friction factor for helium-xenon mixtures in Eq. (19).

Notably, the Karman constant $(\kappa)$ exists in the velocity distribution (see Eq. (3)); as such, the simulated velocity distribution may be numerically fitted to determine $\kappa$ for helium-xenon mixtures. Figure 10a shows that the fitting logarithmic law of velocity for $P r=0.30$ was initially obtained by setting $\kappa=0.42$. Then, a comparison between the calculated logarithmic law with $\kappa=0.42$ and the simulation results of $\operatorname{Pr}=0.21$ was conducted as shown in Fig. 10b. The calculated logarithmic law with $\kappa=0.38$ was still in good agreement with the simulation results; as such, $\kappa=0.42$ was adopted in Eq. (19).

To obtain the appropriate demarcation point of the thermal boundary layer for helium-xenon mixtures, variations in the molecular heat diffusivity $(\alpha)$ and the turbulent heat diffusivity $\left(\varepsilon_{\mathrm{h}}\right)$ were calculated. In this study, the criterion for defining $y_{\text {crit, } \mathrm{T}}^{+}$is that $\alpha=\varepsilon_{\mathrm{h}}$. Figure 11 shows that it is evident that the demarcation points were not fixed for different $P r$; the smaller the $P r$, the farther the demarcation point from the wall. Therefore, it was necessary to establish a model of turbulent thermal diffusivity for helium-xenon mixtures to fix the value of $y_{\text {crit, } \mathrm{T}}^{+}$.

The Reynolds-averaged Navier-Stokes equations (RANS) model was developed based on the Boussinesq eddy viscosity hypothesis [45], in which eddy viscosity was calculated using mixing-length theory; as such, $\varepsilon_{\mathrm{m}} / v$ 


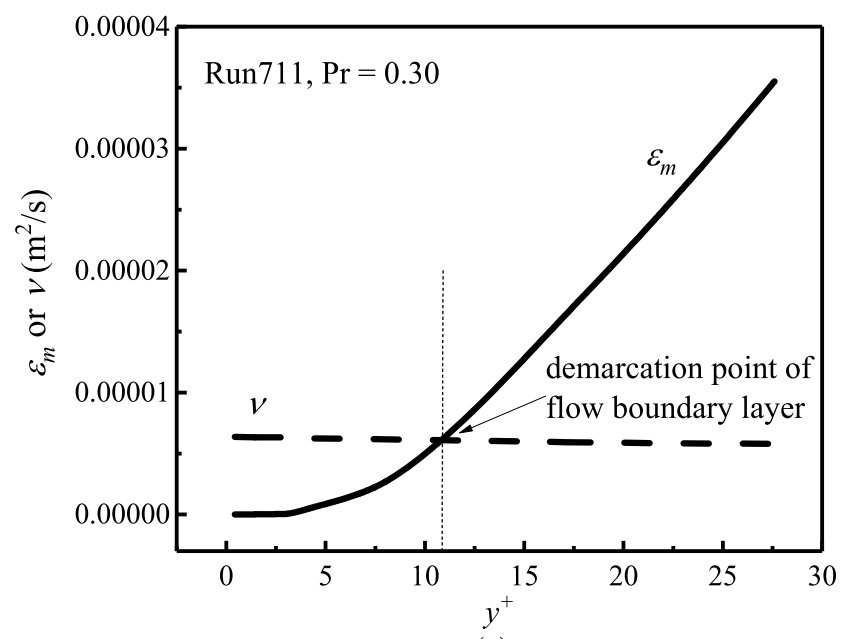

(a)

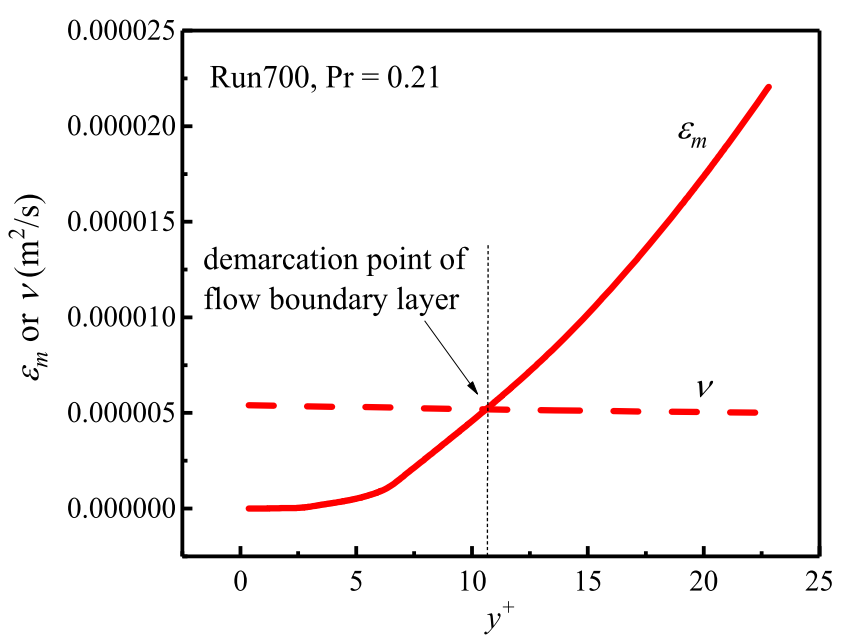

(b)

Fig. 8 (Color online) Variations in molecular viscosity $(v)$ and turbulent momentum diffusivity $\left(\varepsilon_{\mathrm{m}}\right)$ with $y^{+}$for helium-xenon mixtures

Table 3 Four equations used to determine the friction factor

\begin{tabular}{lll}
\hline Name & Formula & Range of application \\
\hline Blasius [42] & $f=0.316 / R e^{0.25}$ & $5.0 \times 10^{3} \leq R e \leq 10^{5}$ \\
Colebrook [43] & $1 / \sqrt{f}=1.8 \lg (R e / 6.9)$ & $5.0 \times 10^{3} \leq R e \leq 5.0 \times 10^{7}$ \\
Drewr [32] & $f=0.0056+0.5 \times R e^{-0.32}$ & $3.0 \times 10^{3} \leq R e \leq 3.0 \times 10^{6}$ \\
Taitel and Dukler [44] & $f=0.184 / R e^{0.2}$ & $R e \geq 3.0 \times 10^{3}$ \\
\hline
\end{tabular}

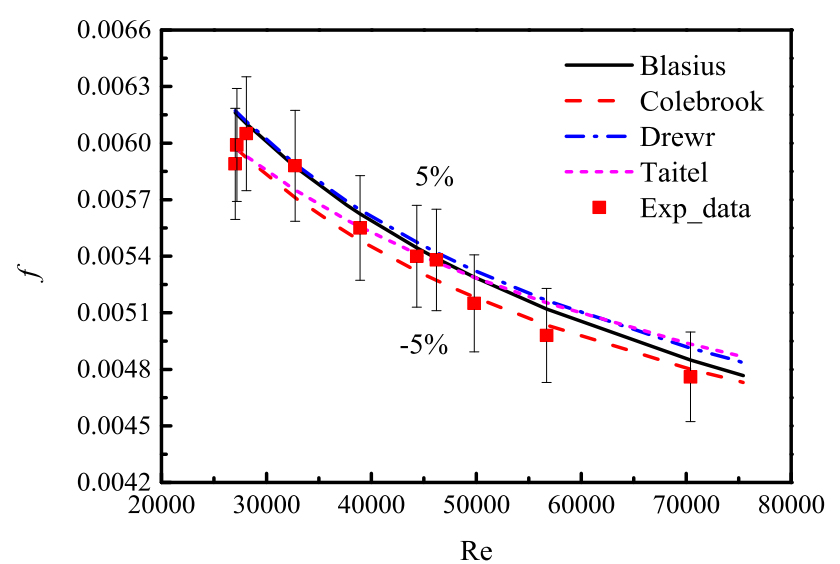

Fig. 9 (Color online) Comparison of calculations using different friction factor equations with experimental data

was a function related only to $y^{+}$. By analyzing the $P r_{\mathrm{t}}$ model (Eqs. (20) and (21)), the $P r_{\mathrm{t}}$ was also found to be a function only related to $y^{+}$for a specific helium-xenon mixture, as $P e_{\mathrm{t}}$ and $R e_{\text {local }}$ were expressed as functions of $y^{+}$. Therefore, the following relationship can be obtained:

$\frac{\varepsilon_{\mathrm{h}}}{v}=\frac{\varepsilon_{\mathrm{m}}}{v} \frac{1}{P r_{\mathrm{t}}}=f\left(y^{+}\right)$.

It is feasible to obtain Eq. (25) by numerical fitting. Since the thermal boundary layer of low- $P r$ helium-xenon mixture was thicker than the flow boundary layer, the fitting range of $y^{+}$should ensure that $y^{+}>11$. First, the expression was initially determined by fitting the simulation results of $P r=0.30$, as shown in Fig. 12(a); this expression could be described by Eq. (26). Thereafter, the cases with the Prandtl number to 0.23 and 0.21 were simulated. The results are shown in Fig. $12 \mathrm{~b}$ and c, where it is shown that the calculation of Eq. (26) was in good agreement with simulated data points. Therefore, for $0.21 \leq \operatorname{Pr} \leq 0.30$ and $y^{+}<50$, Eq. (26) was able to reasonably describe the turbulent heat diffusivity of helium-xenon mixtures.

$\frac{\varepsilon_{\mathrm{h}}}{v}=0.0112\left(y^{+}\right)^{1.82}$

As $\alpha=v / P r$, the $y_{\text {crit, } \mathrm{T}}^{+}$may be determined as follows:

$y_{\text {crit }, \mathrm{T}}^{+}=11.83 \operatorname{Pr}^{-0.55}$.

The influence of the $\operatorname{Pr}$ on turbulent heat transfer may be quantitatively analyzed using the numerical model of the turbulent heat diffusivity. For air and water, the relationship between turbulent heat diffusivity and $y^{+}$was $\varepsilon_{\mathrm{h}} / v \propto$ $\left(y^{+}\right)^{3}[36,37]$. Compared with Eq. (26), it can be seen that the lower Prandtl number will lead to a smaller turbulent thermal diffusivity at the same radial position, resulting in weak convective heat transfer intensity. This conclusion may be used to understand the results in Fig. 2. The Prandtl number of liquid metals was lower than that of the binary 


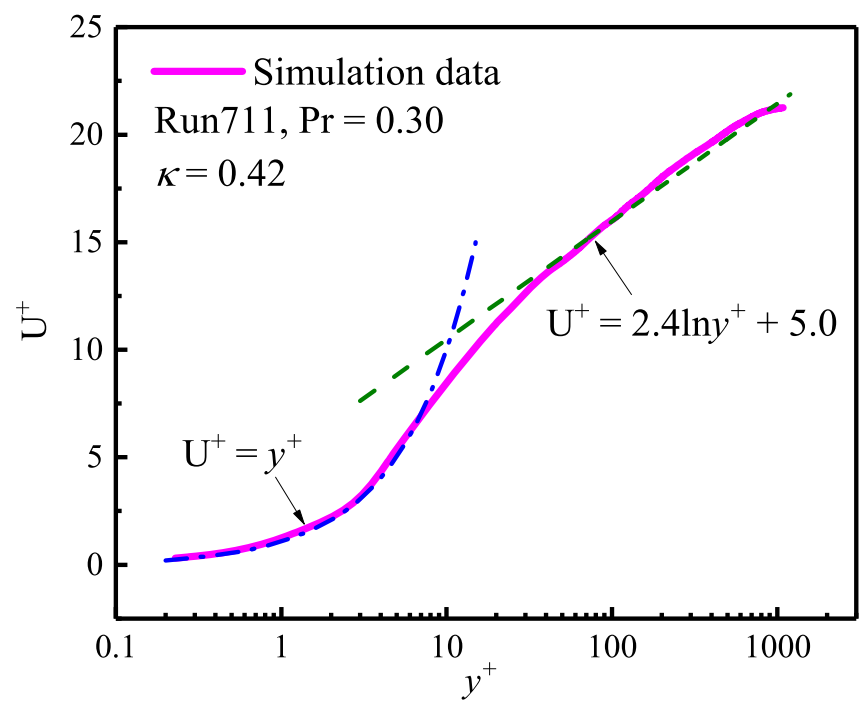

(a)

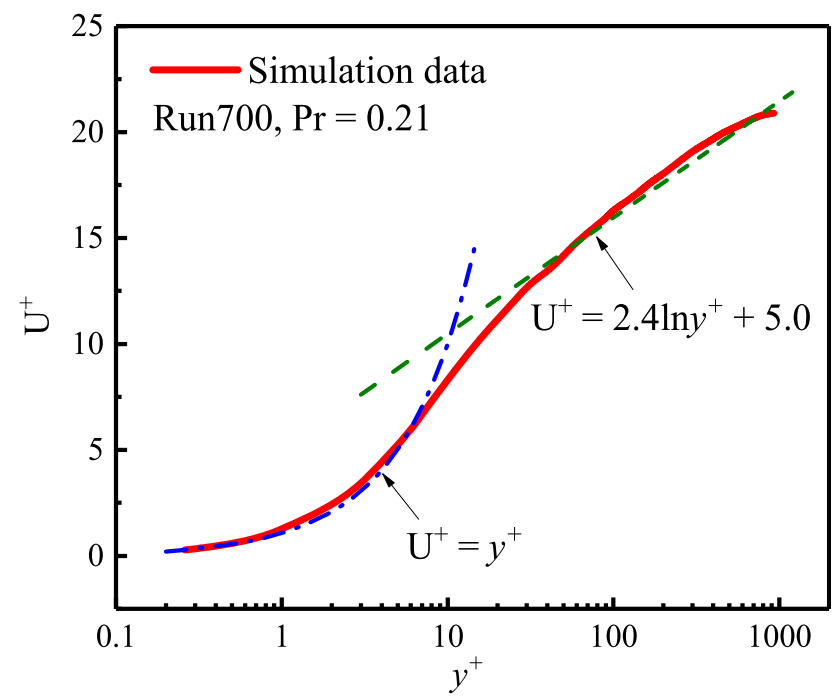

(b)

Fig. 10 (Color online) Fitted velocity profiles of helium-xenon mixtures

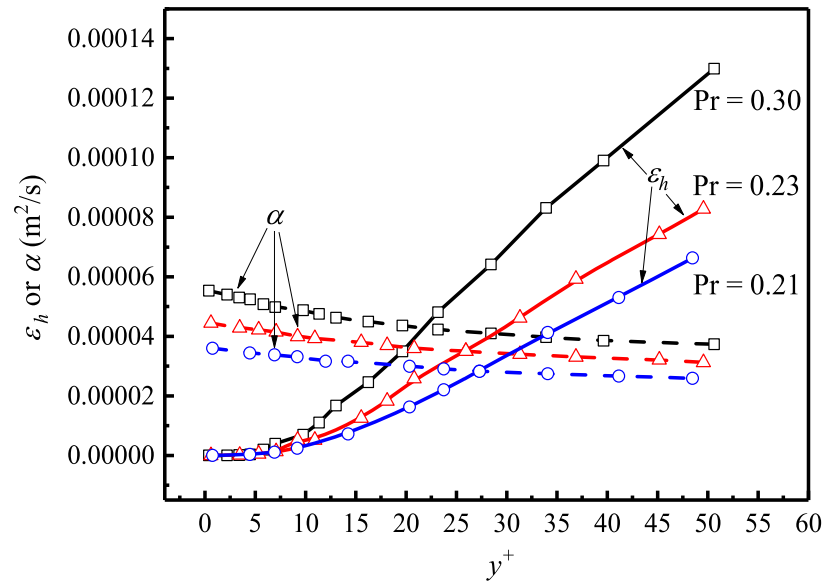

Fig. 11 (Color online)Variations in molecular heat diffusivity $(\alpha)$ and turbulent heat diffusivity $\left(\varepsilon_{\mathrm{h}}\right)$ with the $y^{+}$of helium-xenon mixtures gas mixtures. As the turbulent heat diffusion was weaker for the same $R e$, the Nusselt number correlations obtained from liquid metals underestimated the experimental data of binary gas mixtures. Conversely, the $\mathrm{Pr}$ of conventional fluids was higher than that of helium-xenon mixtures, resulting in more intense turbulent heat diffusion. Therefore, predictions from the DB and Colburn correlations represented overestimations of experimental data.

For working fluids with $\operatorname{Pr} \gg 1.0$, the $P r_{\mathrm{t}}$ tends to be constant of 0.85 . Differently, for low- $P r$ fluids it tends to be larger [46]. However, it is difficult to obtain the section average $P r_{\mathrm{t}}$ directly from the local function expressions. In this study, a constant value was used to roughly represent the section average $P r_{\mathrm{t}}$. To determine this parameter, the radial $P r_{\mathrm{t}}$ distribution of Run711 was first calculated using

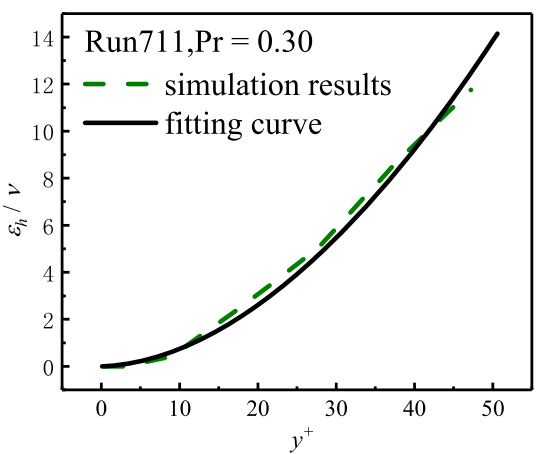

(a)

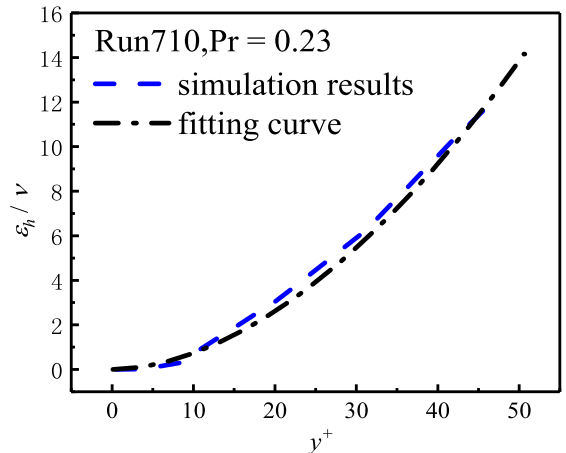

(b)

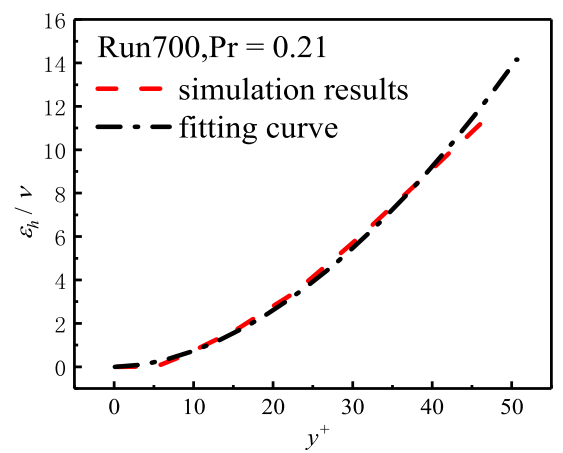

(c)

Fig. 12 (Color online) Numerical fitting of the expression for $\varepsilon_{\mathrm{h}} / v$ 


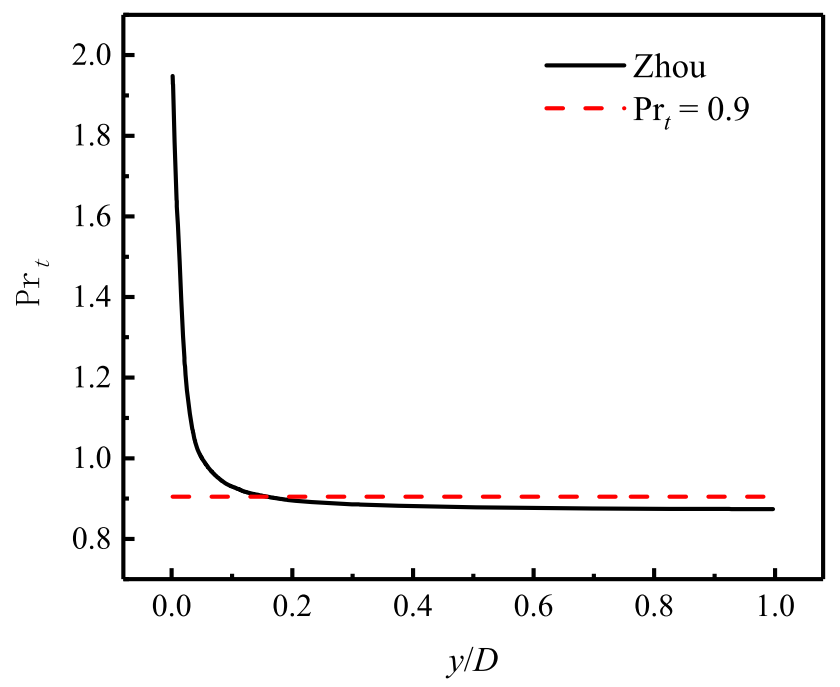

Fig. 13 Radial predictions of $P r_{\mathrm{t}}$ at $x=0.60 \mathrm{~m}$ for Run711

the Zhou $P r_{\mathrm{t}}$ model (Eqs. (20) and (21)). As shown in Fig. 13, by comparing with the prediction of the Zhou model, a $P r_{\mathrm{t}}$ of 0.9 may be a candidate value; as such, this value was initially adopted as the section average $\operatorname{Pr}_{\mathrm{t}}$ in Eq. (19) for the helium-xenon mixtures.

Once all parameters were determined, the semi-theoretical Nusselt number correlation was quantified using Eq. (28):

$N u=\frac{0.20 \operatorname{PrR} e^{0.875}}{4.53 \operatorname{Re}^{0.125}+11.83 \operatorname{Pr}^{0.45}+1.18 \ln \operatorname{Pr}-10.05}$.

\section{Verification and analysis}

Combining Eqs. (4) and (27), the radial temperature distribution of the corresponding helium-xenon mixtures with $0.21 \leq \operatorname{Pr} \leq 0.30$, was determined as shown in Eq. (29):

$$
\left\{\begin{array}{ll}
T^{+}=\operatorname{Pry}^{+}, & y^{+} \leq 11.83 \operatorname{Pr}^{-0.55} \\
T^{+}=3.02\left(\ln y^{+}+0.55 \ln P r-2.47\right)+11.83 \operatorname{Pr}^{0.45}, & y^{+}>11.83 \operatorname{Pr}^{-0.55}
\end{array} .\right.
$$

To verify the correctness of the derivation, the results using Eq. (29) where the $\operatorname{Pr}$ was 0.20, were compared with predictions of other temperature distribution correlations (shown in Table 4). Additionally, the direct numerical simulation results of Kawamura et al. [47] were introduced as benchmarks. As shown in Fig. 14, the calculations using Eq. (29) showed better agreement with the DNS results than those of other correlations, preliminarily proving the validity of Eq. (29) and the correctness of this derivation.

To test the accuracy of the new Nusselt number correlation, predictions using Eq. (28) were compared with experimental data, as shown in Fig. 15. The results show that the calculations are in good agreement with the experimental data of gas mixtures under both working conditions. This further verifies the accuracy of the derivation and its applicability to the turbulent heat transfer for helium-xenon mixtures where $0.21 \leq \operatorname{Pr} \leq 0.30$.

A sensitivity analysis of each parameter was carried out to evaluate the influence of the parameters that were determined on the derived Nusselt number correlation. As the empirical range of the Karman constant was $0.43 \geq$ $\kappa \geq 0.35$, five different constants were tested. Figure 16 shows that even when the value of $\kappa$ fluctuates in the entire empirical range, there is only a very small difference between the calculated Nusselt numbers. This proves that the calculation of the derived Nusselt number correlation is insensitive to $\kappa$. Thereafter, three additional constant $P r_{\mathrm{t}}$ numbers were used for sensitivity analysis. Figure 17 demonstrates that the derived Nusselt number correlations vary with different $P r_{\mathrm{t}}$ numbers. The predictions where $P r_{\mathrm{t}}$ was 0.9 were in better agreement with experimental data, in which a fluctuation of $0.9 \pm 0.1$ appeared to be valid. Additionally, an error propagation analysis of the demarcation point of the flow boundary layer $\left(y_{\text {crit }}^{+}\right)$was also conducted. Figure 18 shows that the calculations where $y_{\text {crit }}^{+}=11$ were closer to experimental data, in which a fluctuation of $11 \pm 1.0$ may also be considered reasonable.

Importantly, helium-xenon mixtures flow through a strongly heated tube in space gas-cooled reactors; under these conditions, the wall temperature is generally higher than the bulk temperature. The physical properties of helium-xenon mixtures at different radial positions will be significantly different. Therefore, the Nusselt number
Table 4 Existing correlations for temperature distribution

\begin{tabular}{lll}
\hline Authors & Correlations & Scope of application \\
\hline Duponcheel et al. [19] & $T^{+}=5 \ln \left(1+0.2 \operatorname{Pry}^{+}\right)$ & $0.01<\operatorname{Pr}<0.025$ \\
Kader [31] & $T^{+}=2.12 \ln y^{+}+\left(3.85 \operatorname{Pr}^{1 / 3}-1.3\right)^{2}-2.12 \ln \operatorname{Pr}$ & $0.025<\operatorname{Pr}<170$ \\
Gowen and Smith [35] & $T^{+}=2.5 \ln y^{+}+5 \ln [(5 \operatorname{Pr}+1) / 30]+8.55+5 \operatorname{Pr}$ & $0.7<\operatorname{Pr}<14.3$ \\
Kays et al. [32] & $T^{+}=2.2 \ln y^{+}+13.39 \operatorname{Pr}^{2 / 3}-5.66$ & $0.7<\operatorname{Pr}<5.9$ \\
\hline
\end{tabular}




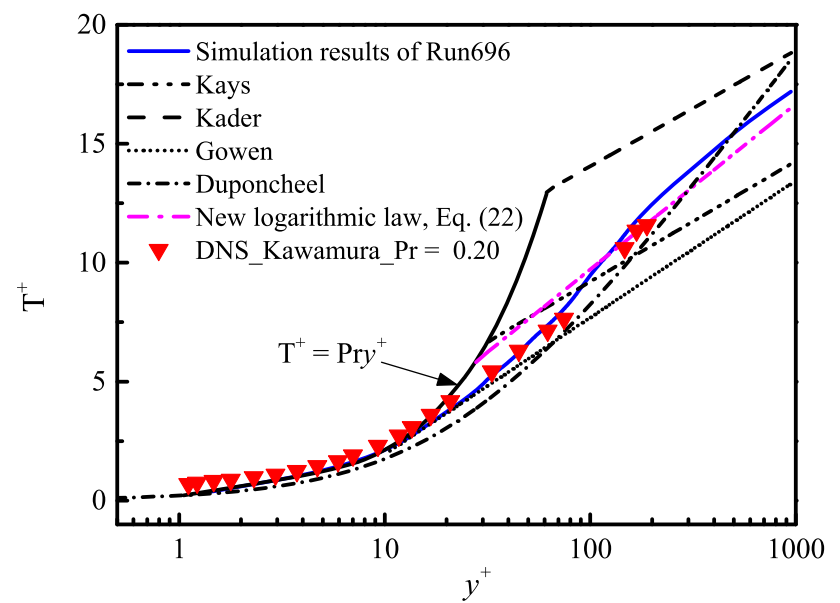

Fig. 14 (Color online) Comparison of prediction by Eq. (29) with other temperature correlations

correlation deduced from constant physical properties may need to be modified. To examine the influence of variable properties on turbulent heat transfer, the Nusselt number calculated using Eq. (28) $\left(N u_{\mathrm{cp}}\right)$ was compared with measured experimental data (Ref. [13]) $\left(N u_{\text {Exp }}\right)$ at various temperature ratios, as shown in Fig. 19.

The ranges of the tested conditions are $18,000<R e<$ 60,000, $0.21 \leq \operatorname{Pr} \leq 0.30$, and $T_{\mathrm{w}} / T_{\mathrm{b}}<2$. Figure 19 shows that the calculation deviation becomes obvious as $T_{\mathrm{w}} / T_{\mathrm{b}}$ increases. When $T_{\mathrm{w}} / T_{\mathrm{b}}=1.8$, the numerical error exceeded $30 \%$. A seemingly exponential relationship between $N u_{\text {Exp }} / N u_{\text {cp }}$ and $T_{\mathrm{w}} / T_{\mathrm{b}}$ was observed when $N u_{\text {Exp }} /$ $N u_{\text {cp }}$ were presented in logarithmic coordinates. Moreover, as $T_{\mathrm{w}} / T_{\mathrm{b}}$ approaches 1.0 , the constant-property correlation would become valid, and $N u_{\text {Exp }} / N u_{\text {cp }}$ would approach 1.0. Therefore, by numerically fitting data points, the modified,

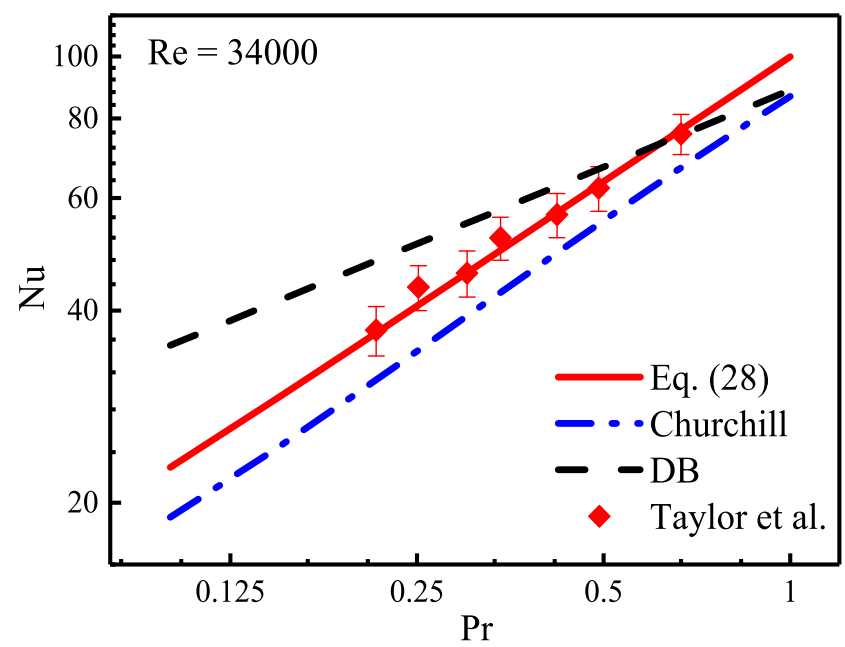

(a)

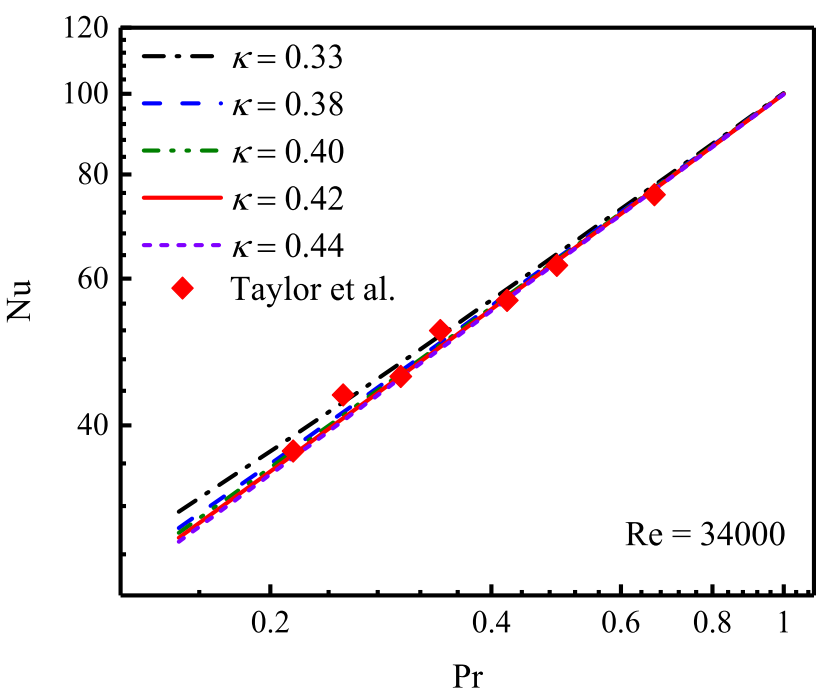

Fig. 16 (Color online) Sensitivity analysis on the Karman constant for the derived Nusselt number correlation

property-variable Nusselt number correlation for the helium-xenon mixture was obtained as follows:

$$
\begin{aligned}
N u_{\mathrm{vp}}= & \frac{0.20 \operatorname{Pr} \operatorname{Re}^{0.875}}{4.53 \operatorname{Re}^{0.125}+11.83 \operatorname{Pr}^{0.45}+1.18 \ln P r-10.05} \\
& \cdot\left(\frac{T_{\mathrm{w}}}{T_{\mathrm{b}}}\right)^{-0.63} \cdot
\end{aligned}
$$

The results in Fig. 19 show that the error in predictions using Eq. (30) was almost within 5\% and was consistently within $10 \%$. Notably, the modified Nusselt correlation (Eq. (30)) was only determined using existing and limited experimental data; to fully verify its applicability, additional experimental data are required.

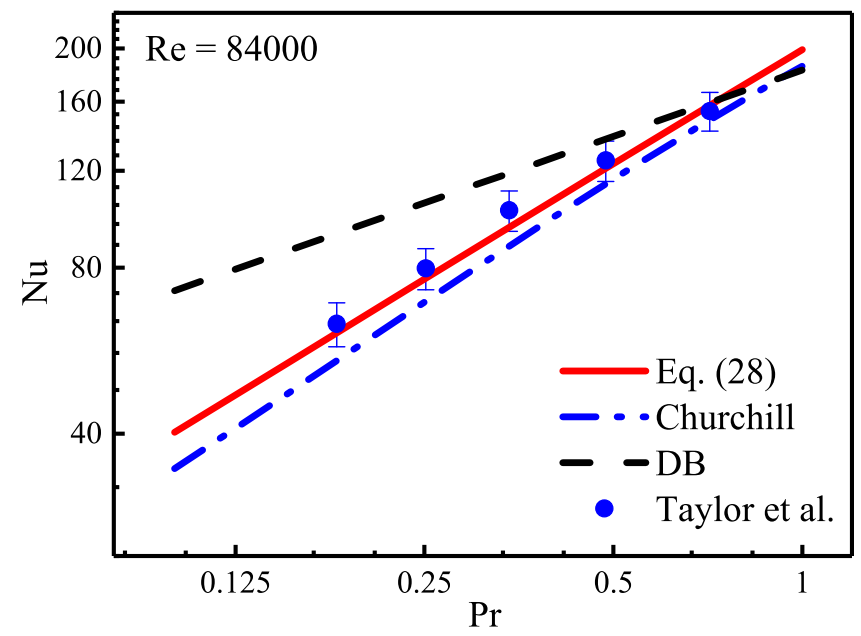

(b)

Fig. 15 (Color online) Comparison of predictions using Eq. (28) with experimental data 


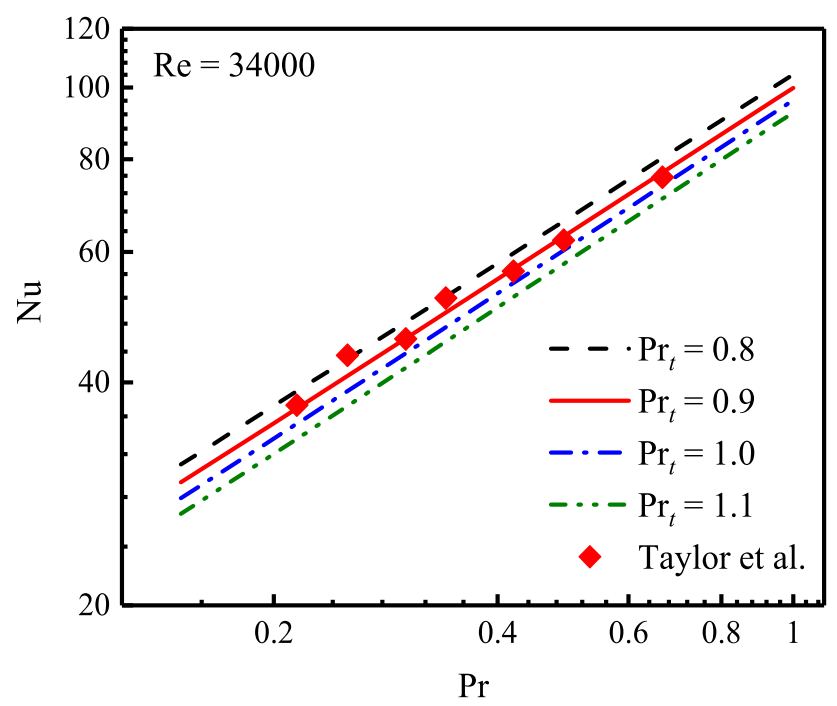

Fig. 17 (Color online) Sensitivity analysis on the $P r_{\mathrm{t}}$ number for derived Nusselt number correlation

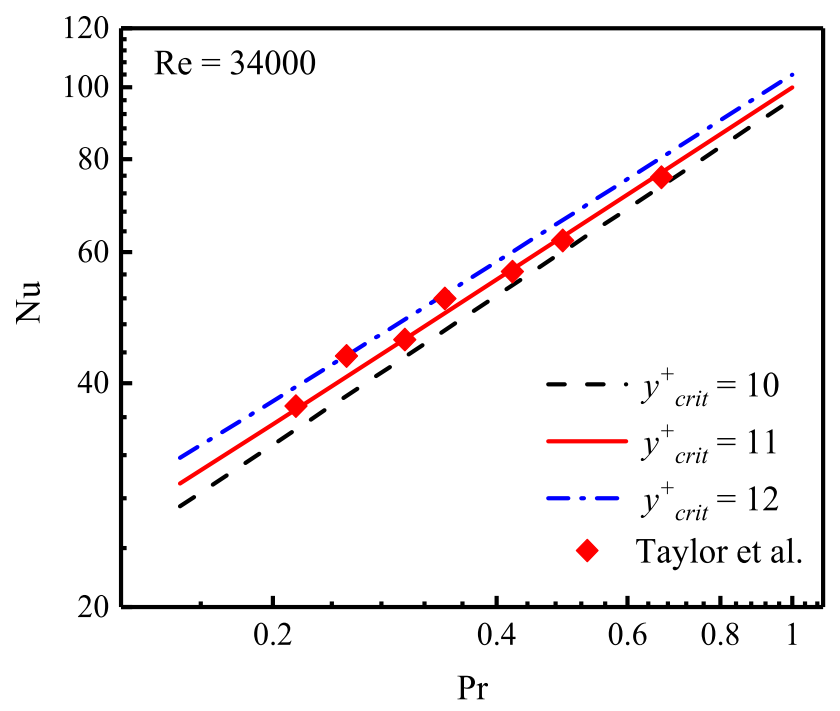

Fig. 18 (Color online) Sensitivity analysis on the $y_{\text {crit }}^{+}$for derived Nusselt number correlation

\section{Conclusion}

This study evaluates existing Nusselt number correlations and derives a theoretical Nusselt number correlation for helium-xenon mixtures using turbulent boundary layer theory. The turbulent heat transfer in a tube for heliumxenon mixtures was numerically simulated using a modified $P r_{\mathrm{t}}$ model. Based on numerical simulations, a new turbulent heat diffusivity model in the thermal boundary layer was developed, and related parameters were determined in the theoretical Nusselt number expression. A preliminary modified Nusselt number correlation was

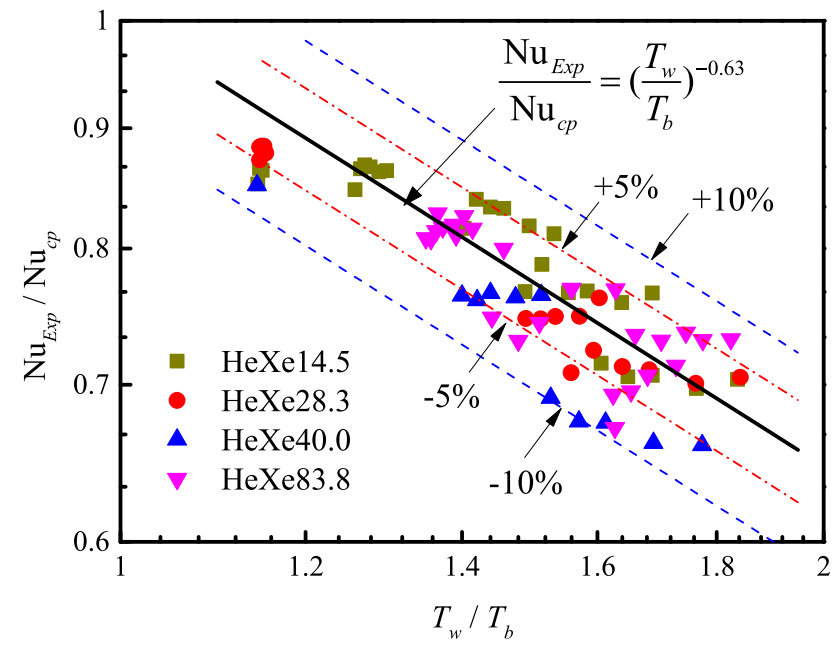

Fig. 19 (Color online) Comparison of calculations using Eq. (28) with measured experimental data

presented based on variations in gas properties. The main conclusions from this study were:

(1) Compared with the extrapolated experimental data of gas mixtures, the selected Nusselt number correlations from conventional fluids and liquid metals were unsuitable for helium-xenon mixtures with $0.21 \leq \operatorname{Pr} \leq 0.30$;

(2) The calculation error of the friction factor for helium-xenon mixtures using the Blasius equation was within $5 \%$, and the demarcation point of $\mathrm{U}^{+}$for helium-xenon mixtures and conventional fluids was approximately equal;

(3) For $0.21 \leq P r \leq 0.30$ and $y^{+}<40$, $\varepsilon_{\mathrm{h}} / v=0.0112\left(y^{+}\right)^{1.82}$ can reasonably describe the turbulent heat diffusivity of helium-xenon mixtures. A lower Pr led to a reduced turbulent thermal diffusivity, resulting in weak convective heat transfer intensity;

(4) Predictions by the derived semi-theoretical Nusselt number correlation were in good agreement with experimental data, verifying the accuracy of the derivation and its applicability to turbulent heat transfer for helium-xenon mixtures.

Future research should focus on obtaining additional experimental research on low- $P r$ helium-xenon mixtures. This additional experimental data may be used to verify correlations proposed in this study. Furthermore, the new Nusselt number correlation should be used to develop a thermal-hydraulic transient analysis code for heliumxenon cooled reactor systems.

Open Access This article is licensed under a Creative Commons Attribution 4.0 International License, which permits use, sharing, adaptation, distribution and reproduction in any medium or format, as 
long as you give appropriate credit to the original author(s) and the source, provide a link to the Creative Commons licence, and indicate if changes were made. The images or other third party material in this article are included in the article's Creative Commons licence, unless indicated otherwise in a credit line to the material. If material is not included in the article's Creative Commons licence and your intended use is not permitted by statutory regulation or exceeds the permitted use, you will need to obtain permission directly from the copyright holder. To view a copy of this licence, visit http://creativecommons. org/licenses/by/4.0/.

Author contributions All authors contributed to the study conception and design. Material preparation, data collection and analysis were performed by Biao Zhou, Yu Ji, Jun Sun and Yu-Liang Sun. The first draft of the manuscript was written by Biao Zhou and all authors commented on previous versions of the manuscript. All authors read and approved the final manuscript.

\section{References}

1. M.S. El-Genk, T.M. Schriener, Long operation life reactor for lunar surface power. Nucl. Eng. Des. 241, 2339-2352 (2011). https://doi.org/10.1016/j.nucengdes.2011.02.024

2. T. Howe, S. Howe, J. Miller, Novel deep space nuclear electric propulsion spacecraft. Nucl. Technol. 207, 866-875 (2020). https://doi.org/10.1080/00295450.2020.1832814

3. C. Wang, T. Liu, S. Tang et al., Thermal-hydraulic analysis of space nuclear reactor TOPAZ-II with modified RELAP5. Nucl. Sci. Tech. 30, 12 (2019). https://doi.org/10.1007/s41365-0180537-3

4. M.S. El-Genk, J.P. Tournier, Noble gas binary mixtures for closed-Brayton-cycle space reactor power systems. J. Propul. Power. 23, 863-873 (2007). https://doi.org/10.2514/1.27664

5. J.P. Tournier, M.S. El-Genk, Properties of noble gases and binary mixtures for closed Brayton Cycle applications. Energy Convers. Manag. 49, 469-492 (2008). https://doi.org/10.1016/j.enconman. 2007.06.050

6. L.S. Mason, A comparison of Brayton and stirling space nuclear power systems for power levels from 1 kilowatt to 10 megawatts. Proc. Am. Inst. Phys. Conf. (2001). https://doi.org/10.1063/1. 1358045

7. X. Zhang, D. She, F. Chen et al., Temperature analysis of the HTR-10 after full load rejection. Nucl. Sci. Tech. 30, 163 (2019). https://doi.org/10.1007/s41365-019-0692-1

8. B.M. Gallo, M.S. El-Genk, Brayton rotating units for space reactor power systems. Energy Convers. Manag. 50, 2210-2232 (2009). https://doi.org/10.1016/j.enconman.2009.04.035

9. M.S. El-Genk, J.P. Tournier, Noble gas binary mixtures for gascooled reactor power plants. Nucl. Eng. Des. 238, 1353-1372 (2008). https://doi.org/10.1016/j.nucengdes.2007.10.021

10. T. Meng, K. Cheng, F. Zhao et al., Computational flow and heat transfer design and analysis for 1/12 gas-cooled space nuclear reactor. Ann. Nucl. Energy. 135, 106986 (2020). https://doi.org/ 10.1016/j.anucene.2019.106986

11. Z.G. Li, J. Sun, M.G. Lang et al., Design of a hundred-kilowatt level integrated gas-cooled space nuclear reactor for deep space application. Nucl. Eng. Des. 361, 110569 (2020). https://doi.org/ 10.1016/j.nucengdes.2020.110569

12. T.M. Schriener, M.S. El-Genk, Effects of decreasing fuel enrichment on the design of the pellet bed reactor (PeBR) for lunar outpost. Prog. Nucl. Energy. 104, 288-297 (2018). https:// doi.org/10.1016/j.pnucene.2017.10.010

13. V.I. Solonin, A.A. Satin, A.A. Dunaitsev et al., Hydrodynamic characteristics of coolant tracts in high-temperature gas-cooled nuclear reactor. Atom. Energy. 124, 302-308 (2018). https://doi. org/10.1007/s10512-018-0414-5

14. F.W. Dittus, L.M.K. Boelter, Heat transfer in automobile radiators of the tubular type. Int. Commun. Heat Mass Transf. 12, 3-22 (1985). https://doi.org/10.1016/0735-1933(85)90003-X

15. A.P. Colburn, A method of correlating forced convection heattransfer data and a comparison with fluid friction. Int. J. Heat Mass Transf. 7, 1359-1384 (1964). https://doi.org/10.1016/00179310(64)90125-5

16. P.E. Pickett, M.F. Taylor, D.M. McEligot, Heated turbulent flow of helium-argon mixtures in tubes. Int. J. Heat Mass Transf. 22, 705-719 (1979). https://doi.org/10.1016/0017-9310(79)90118-2

17. M.F. Taylor, K.E. Bauer, D.M. McEligot, Internal forced convection to low-Prandtl-number gas mixtures. Int. J. Heat Mass Transf. 31, 13-25 (1988). https://doi.org/10.1016/00179310(88)90218-9

18. A. Shams, A.D. Santis, L.K. Koloszar et al., Status and perspectives of turbulent heat transfer modelling in low-Prandtl number fluids. Nucl. Eng. Des. 353, 110220 (2019). https://doi. org/10.1016/j.nucengdes.2019.110220

19. M. Duponcheel, L. Bricteux, M. Manconi et al., Assessment of RANS and improved near-wall modeling for forced convection at low Prandtl numbers based on LES up to $R e_{\tau}=2000$. Int. J. Heat Mass Transf. 75, 470-482 (2014). https://doi.org/10.1016/j. ijheatmasstransfer.2014.03.080

20. O.V. Vitovsky, M.S. Makarov, V.E. Nakoryakov et al., Heat transfer in a small diameter tube at high Reynolds numbers. Int. J. Heat Mass Transf. 109, 997-1003 (2017). https://doi.org/10. 1016/j.ijheatmasstransfer.2017.02.041

21. A. Shams, A.D. Santis, Towards the accurate prediction of the turbulent flow and heat transfer in low-Prandtl fluids. Int. J. Heat Mass Transf. 130, 290-303 (2019). https://doi.org/10.1016/j. ijheatmasstransfer.2018.10.096

22. L. Bricteus, M. Duponcheel, G. Winckelmans et al., Direct and large eddy simulation of turbulent heat transfer at very low Prandtl number: application to lead-bismuth flows. Nucl. Eng. Des. 246, 91-97 (2012). https://doi.org/10.1016/j.nucengdes. 2011.07.010

23. O. Zier, W. Zimmermann, W. Pesch, On low-Prandtl-number convection in an inclined layer of liquid mercury. J. Fluid Mech. 874, 76-101 (2019). https://doi.org/10.1017/jfm.2019.432

24. R.N. Lyon, Liquid metal heat-transfer coefficients. Chem. Eng. Prog. 47, 75-79 (1951)

25. N.Z. Azer, B.T. Chao, A mechanism of turbulent heat transfer in liquid metals. Int. J. Heat Mass Transf. 1, 121 (1960). https://doi. org/10.1016/0017-9310(60)90016-8

26. R.H. Notter, C.A. Sleicher, Solution to turbulent Graetz problem. 3. fully developed and entry region heat-transfer rates. Chem. Eng. Sci. 27, 2073 (1972). https://doi.org/10.1016/00092509(72)87065-9

27. F. Chen, X.L. Huai, J. Cai et al., Investigation on the applicability of turbulent-Prandtl-number models for liquid lead-bismuth eutectic. Nucl. Eng. Des. 257, 128-133 (2013). https://doi.org/10. 1016/j.nucengdes.2013.01.005

28. X. Cheng, N. Tak, Investigation on turbulent heat transfer to leadbismuth eutectic flows in circular tubes for nuclear applications. Nucl. Eng. Des. 236, 385-393 (2006). https://doi.org/10.1016/j. nucengdes.2005.09.006

29. S.W. Churchill, Comprehensive correlating equations for heat, mass and momentum transfer in fully developed flow in smooth tubes. Ind. Eng. Chem. Fundam. 16, 109-116 (1977). https://doi. org/10.1021/i160061a021

30. B. Zhou, Y. Ji, J. Sun et al., Modified turbulent Prandtl number model for helium-xenon gas mixture with low Prandtl number. Nucl. Eng. Des. 366, 110738 (2020). https://doi.org/10.1016/j. nucengdes.2020.110738 
31. B.A. Kader, Temperature and concentration profiles in fully turbulent boundary layers. Int. J. Heat Mass Transf. 24, 1541-1544 (1981). https://doi.org/10.1016/0017-9310(81)902209

32. W.M. Kays, M.E. Crawford, B. Weigand, Convective Heat and Mass Transfer, vol. 4 (McGraw-Hill Science, New York, 2005)

33. H. Schlichting, K. Gersten, E. Krause, Boundary-Layer Theory (Springer, New York, 2017)

34. B. Weigand, J.R. Ferguson, M.E. Crawford, An extended Kays and Crawford turbulent Prandtl number model. Int. J. Heat Mass Transf. 40, 4191-4196 (1997). https://doi.org/10.1016/S00179310(97)00084-7

35. R.A. Gowen, J.W. Smith, The effect of the Prandtl number on temperature profiles for heat transfer in turbulent pipe flow Chem. Eng. Sci. 22, 1701 (1967). https://doi.org/10.1016/00092509(67)80205-7

36. S. Aravinth, Prediction of heat and mass transfer for fully developed turbulent fluid flow through tubes. Int. J. Heat Mass Transf. 43, 1399-1408 (2000). https://doi.org/10.1016/S00179310(99)00218-5

37. Q.J. Slaiman, M.M. Abu-Khader, B.O. Hasan, Prediction of heat transfer coefficient based on eddy diffusivity concept prediction of heat transfer coefficient based on Eddy Diffusivity Concept. Eng. Res. Des. 85, 455-464 (2007). https://doi.org/10.1205/ cherd06002

38. H. Zhao, X. Li, X. Wu, New friction factor and Nusselt number equations for turbulent convection of liquids with variable properties in circular tubes. Int. J. Heat Mass Transf. 124, 454-462 (2018). https://doi.org/10.1016/j.ijheatmasstransfer. 2018.03.082
39. B.A. Kader, A.M. Yaglom, Heat and mass-transfer laws for fully turbulent wall flows. Int. J. Heat Mass Transf. 15, 2329-3000 (1972). https://doi.org/10.1016/0017-9310(72)90131-7

40. J.P. Tournier, M.S. El-Genk, B.M. Gallo, Best estimates of binary gas mixtures properties for closed Brayton cycle space applications. in Proceedings of 4th International Energy Conversion Engineering Conference and Exhibit (2006)

41. B. Zhou, Y. Ji, J. Sun et al., CFD simulations of the heliumxenon mixture flow and heat transfer, in Proceedings of International Conference on Nuclear Engineering (2019)

42. N. Rott, Note on the history of the Reynolds number. Rev. Fluid Mech. 22, 1-11 (1990). https://doi.org/10.1146/annurev.fl.22. 010190.000245

43. C.F. Colebrook, C.M. White, Experiments with fluid friction in roughened pipes, in Proceedings of the Royal Society of London Series A-Mathematical and Physical Sciences (1937)

44. Y. Taitel, A.E. Dukler, A model for predicting flow regime transitions in horizontal and near horizontal gas-liquid flow. AICHE J. 22, 47-55 (1976). https://doi.org/10.1002/aic. 690220105

45. J. Grifoll, F. Giralt, The near wall mixing length formulation revisited. Int. J. Heat Mass Transf. 43(19), 3743-3746 (2000). https://doi.org/10.1016/S0017-9310(00)00009-0

46. W.M. Kays, Turbulent Prandtl number-where are we. J. Heat Transf.-Trans ASME. 116, 284-295 (1994). https://doi.org/10. $1115 / 1.2911398$

47. H. Kawamura, K. Ohsaka, H. Abe et al., DNS of turbulent heat transfer in channel flow with low to medium-high Prandtl number fluid. Int. J. Heat Mass Transf. 19, 482-491 (1998). https://doi. org/10.1016/S0142-727X(98)10026-7 